\title{
Commitment of medical graduates educated with and without community-based medical education towards community health care-A study from Malaysia.
}

\author{
Shahid Hassan \\ Unit of Medical Education, Faculty of Medicine and Health Sciences, Universiti Putra Malaysia, Malaysia
}

\section{ARTICLE INFO}

Received : 29/01/2013

Accepted : : 29/06/2013

Published : : 01/12/2013

\section{KEYWORD}

Community-based medical education

Community oriented education,

Medical graduates, Community commitments and health care.

\section{ABSTRACT}

Context: Community-based medical education (CBME) has become widely accepted as an important innovation in undergraduate medical education. In curriculum featuring CBME, students are acquainted with the community early in their studies however; the impact of this training can be judged best to see them practice the required aspects of CBME. Malaysia is a multiracial country with a very strong community dependant life style. Main national health problems have called for a change in health profession education from traditional hospital based health care to community-based delivery system. Three major university's medical schools that either practice community oriented or community based medical education in undergraduate medical curriculum are evaluated. Universiti Sains Malaysia (USM) has a community based medical education (CBME) curriculum as Community and Family Case Study (CFCS) compared to a community oriented education curriculum (COE) adopted by Universiti Malaya (UM) and Universiti Kebangsaan Malaysia (UKM). However, UM at the time of undertaking this study back in 2005 was though practicing COE has also later opted CBME as CFCS. Objective: To determine whether medical graduates from USM with a community-based medical education in its curriculum for more than 25 years are inspired to have stronger commitment towards community health as shown in their on-job practice of medicine compared to other graduates from UM and UKM, who have adopted community-oriented medical education program. Method: A questionnaire-based pilot study with 12 items (variables) was designed to obtain supervisor's opinion on commitment of interns towards the health of community they serve. The questionnaire was administered to a randomized group of 85 specialists supervising the internship training program in five major disciplines including internal medicine, surgery, orthopaedic, gynaecology and obstetrics and paediatric medicine. The data received from 62 respondents from five major disciplines was analyzed utilizing SPSS version 12.0.1. Result: The responses received from 62 supervisors on an inventory in which 9 out of 12 variables were directly related to community commitments of interns. It was shown that the USM graduates who were taught through a CBME curriculum have performed better than the graduates from UM and UKM who followed a COE curriculum. P-value (< 0.001) was highly significant and consistent with higher mean score in those variables. Conclusion: The graduates taught through a CBME curriculum performed better in community commitments towards patients care compared to graduates from COE curriculum.

(C) Medical Education Department, School of Medical Sciences, Universiti Sains Malaysia. All rights reserved.

CORRESPONDING AUTHOR: Professor Dr Shahid Hassan, Unit of Medical Education, Faculty of Medicine and Health Sciences, Universiti Putra Malalysia, Email: shahid@medic.upm.edu.my 


\section{Introduction}

A number of medical schools have adopted community-based medical education in their under-graduate medical curricula globally. Most important purposes of CBME program are to enable students experience and understand the health need of society and potentials of community based organizations [1]. CBME introduces students to full spectrum of health care [2]. Besides, it also advocates public health approaches in assessing the health needs of community [3], which may start as a case study at hospital level. An ideal COE program aims at health professional education based on main health problem of the society in which the educational institution is located. But community involvement and it's placement in the curriculum as a stakeholder together with students active participation in studying and addressing the health problem of community makes it community based education (CBME). Thus, CBME is a way of implementing a community oriented education (COE) program to achieve educational relevance to community needs.

Three main issues are important in the innovation of undergraduate medical education to make it more community-oriented and more inclusive of community-based education [4]. The first issue relates to student's exposure to type of patients they encounter during their clinical training in hospital compared to type of patients they will be treating in primary health care centers (PHC) or periphery district hospitals as medical officers after graduation. The second issue concerns the recent changes in the understanding of health delivery system globally, which gives emphasis to health promotion and prevention of diseases rather than the advances in technology towards diagnostic and curative care $[5,6]$. This is to emphasize a medical student's training as a health team manager. The third issue is about inequity in access to health services by every member of community whether living in rural or urban communities.

One of the rationales of CBME is to train students to develop more sense of responsibility and leadership qualities compared to their peers in traditional medical education [7]. The doctors produced through the CBME curricula should possess professional behavior with community notion as compared to doctors produced through traditional curricula. Malaysian health delivery system under seventh national plan [8] (keeping in view the year of study back in 2005) emphasizes the need to promote community health care that aims at preventive measures at grass root level of any public health program. Malaysia where majority people still live in rural areas has a strong community system.

\section{CBE curricula of three medical schools in Malaysia}

\section{Faculty of Medicine, Universiti Malaya (UM)}

In UM's COE programme (before 2005), students generally follow a patient from year one to year five. Students work in pairs derived from groups of 16 to 18 members. At least two home visits per year are expected from the student pairs. At each visit, students gather information on the patient and his/her family. Time is setaside in the curriculum for students to make their visits in each calendar year. Debriefing sessions for all groups enable students to share their visit experiences with each other and with tutors and group coordinators. UM at the time of undertaking this study back in 2005 was though practicing COE has also later opted CBME as CFCS.

\section{Faculty of Medicine, Universiti Kabangsang Malaysia (UKM)}

COE at UKM primarily focuses on a community medicine posting for a period of four weeks, which includes one week posting to a district hospital and a three-week off and on visits to a village of a nearby rural community. Students are supposed to stay in a house rented for this purpose somewhere close to the community they visit. The primary aim of the program is to expose the student to the organization of district health care. A critical appraisal of the roles of various health care professionals and of the district medical officer is encouraged. 
School of Medical Sciences, Universiti Sains Malaysia (USM)

CBME program of USM is stretched over a period of five years, starting in year one to finish in year five and is known as the Community and Family Case Study (CFCS) program. CFCS is incorporated in a typically practiced SPICES model [9] of undergraduate medical education, which runs spirally to deliver the curriculum. In year two students conduct a survey to identify community health issues. In year three, each student adopts a patient through whom they seek access to family and the community. All findings contribute to a final collective group programme implemented in year four and year five to promote community development. The student's work under a contract (contract learning) signed between them and the supervisors. Every year an exhibition is organized for final year students to acknowledge and reward their work in the community they are posted. Emphasis CBME program of USM is on developing a partnership between school and the community.

\section{Methods}

This study is based on a questionnaire administered to a group of respondents supervising the recently graduated interns who have been working in various Ministry of Health-affiliated hospitals scattered throughout the West Malaysia from east to west and from north to south. Only those hospitals, which have been accredited by the Malaysian Inter Universities Conjoint Board for Postgraduate Training, were included in the study. Sample size calculation was based on the assumption (prevalence of $10 \%$ ) of community-oriented doctors as analyzed from the available published literature from Malaysia [10]. The indication of community orientation in this study is assumed from the preferences made by students to choose community medicine and family medicine as the disciplines for their post-graduate program compared to those who showed their interest in high-tech hospital based disciplines. Keeping with 95\% confidence level (alpha $=0.05$ ) and a precision of $7 \%$ [11] we calculated 70.56 subjects for this study. After adjustment for $20 \%$ expected non-response the sample size estimated was 84.67 (i.e. 85).

Supervisors were randomly selected from each hospital out of five major disciplines (general surgery, orthopedic, internal medicine, obstetrics and gynecology and pediatric medicine). Each of these departments generally has four to eight specialists. Interns from UM, UKM and USM rated by their supervisors have been observed by them for 6 months to 1 year. Three questionnaires were administered to every supervisor, one each to rate interns graduated from UM, UKM and USM. The questionnaire comprised of 12 items. Items 1-9 (see appendix) addressed community commitment of the interns observed for their concern for patients and their approach towards community health care. The questionnaire developed included items that were structured to reflect the comparative degree of community commitments of interns of three medical schools as observed by the supervisors. The other three items (10-12) addressed the intern's preference for specialization, interpersonal skills and sense of self-directed learning (see appendix).

Assumptions were drawn from comparative positive responses of respondents towards better community commitments of interns noticed from their on-job behavior and attitudes for patients care. However, the items in questionnaire did not specifically ask, for example the exact number of visits paid by any particular group of interns to patient's resident or their community. Similarly the efforts to find out exact number of lost to follow up patients to ensure their drugs compliance or family and community support were not established. Interns were rather compared from one another for their community commitments observed from their on-job performance as perceived through nine variables (items) by the respective supervisors.

The questionnaire was pre-tested and validated in usual manner by administering it to 12 lecturers (medical specialist) of three-selected disciplines of USM (obstetrics and gynaecology, orthopaedic and pediatric medicine, using an English version. Difficulties in terms of 
language, mode of question and misinterpretation in understanding the questions by any respondents were thoroughly assessed for each item in the presence of principal researcher. Minor adjustments were made in variables depending on the feedback received from this pilot project. Need to translate the questionnaire into Malay language was not felt. A short description, how to answer each item was also sent together with the questionnaire to respondents in final study.

The data was analyzed using SPSS version 12.0.1. Chi-square test was applied to compare ratings of interns from the three universities with respect to their community commitments (see appendix). Sixty-two out of 85 supervisors approached have filled in all three questionnaires (response rate $73 \%$ ). Information regarding supervisor's parent institution of graduation was also obtained to analyze possibility of any bias (see table 1). Responses received from the respondents were later regrouped into above average (excellent and good), average (fair) and below average poor and very poor) for descriptive analysis (see table 2).

Scores obtained on items 10, 11 and 12 qualified for ANOVA as the homogeneity of variance assumption was met for these items ( $p=0.115$, 0.600 , and 0.147 respectively). The ANOVA results were highly significant $(p<0.001)$ for these items. Consequently, the Bonferroni Post Hoc Test for multiple comparisons was run (see table 3).

\section{Result}

The respondents frequency table indicates that majority of the respondents (supervisors) were from UM that is 24 (38.7\%) followed by UKM 22 (22.6\%), Overseas qualified 13 (21.0\%) and USM 11 (17.7\%) (See table 1).

The descriptive analysis of Intern's university of graduation suggest that the USM interns have performed better than the other two medical schools (UM and UKM) in their mean scores for all the variables (variables 1-9) related to community care (see figure and table 2). The $p$ - values of variables related to community commitments (variable 1-9) inclusive of variable 10 (career preferences) were found highly significant $(<0.001)$.

Table 1: Frequency statistics of respondents as supervisors' and their university of graduation from three medical schools.

\begin{tabular}{|l|c|c|}
\hline $\begin{array}{l}\text { Respondent's (supervisors) medical } \\
\text { school and university of graduation }\end{array}$ & $\mathrm{n}$ & $\%$ \\
\hline $\begin{array}{l}\text { School of Medical Sciences, } \\
\begin{array}{l}\text { University Science Malaysia } \\
\text { (USM) }\end{array}\end{array}$ & 11 & 17.7 \\
\hline $\begin{array}{l}\text { Faculty of Medicine, University of } \\
\text { Malaya (UM) }\end{array}$ & 24 & 38.7 \\
\hline $\begin{array}{l}\text { Faculty of Medicine, University } \\
\text { Kabangsang Malaysia (UKM) }\end{array}$ & 14 & 22.6 \\
\hline $\begin{array}{l}\text { Overseas Medical Schools } \\
\text { Total }\end{array}$ & 13 & 21.0 \\
\hline
\end{tabular}

However, in interpersonal skills UM interns mean scores (SD) was 4.26 (0.68) compared to USM 3.37(0.73) and UKM 2.19 (0.96). In selfdirected learning USM interns showed higher mean (SD) scores of 3.42 (0.95) compared to UM 3.32 (1.1) and UKM 2.69 (0.95). Similarly in career preferences (variable 10) for choosing disciplines reflecting community health care practice verses high - tech hospital based disciplines it was observed that the USM graduates showed a clearly higher mean scores (SD) of 3.58 (1.049) compared to UM 2.82 (1.153) and UKM 2.87 (.914).

For interpersonal skills, 57(90.3\%) out of 62 respondents graded UM interns as above average compared to 24 (38.7\%) for USM interns and 7 (11.3\%) for UKM interns as above average. (see table 2) About self-directed learning and continuing professional development, USM interns were graded higher that is 34 (54.8\%) than the interns of UM 28 (45.20\% and UKM 14 (22.60\%)

For variables 10-12 ANOVA was carried out with $p$-value $=0.115, \quad 0.600$ and 0.147 respectively). Post Hoc Test for multiple comparisons consequently analyzed the abovementioned variables (see table 3). For the interpersonal skills each university's interns were 
significantly different (p-value $<0.001$ ) in their USM and UKM, where as in other two variables (variable 10 and 12) USM graduates were found to be more influenced with the teaching of CBME with emphasis on self-directed learning and preferences for community service as one of those objectives.

A descriptive statistics analyzed the supervisor's bias towards interns if they were to be found from the same institution of undergraduate study
However it was found that the UM supervisor have assigned above average scores to majority of USM interns compared to UM and UKM graduates (see table 3). It is only for the variable querying sustainable community support (item 4 in questionnaire, see appendix) that UM supervisor have rated the UM and UKM interns ahead of USM interns in the above average category ( 7 vs. 5 , see table 2 )

Table 3: Bonferroni Post Hoc Test for multiple comparisons applicable to three variables with mean difference significant at the 0.05 levels

\begin{tabular}{|c|c|c|c|c|}
\hline Dependent variable & University (I) & $\begin{array}{l}\text { Universities } \\
\text { compared (J) }\end{array}$ & Mean diff. (I-J) & p-value \\
\hline \multirow[t]{6}{*}{ Interpersonal skills } & \multirow[t]{2}{*}{ USM } & UM & -887 & $<0.001$ \\
\hline & & UKM & 1.177 & $<0.001$ \\
\hline & \multirow[t]{2}{*}{ UM } & USM & 0.887 & $<0.001$ \\
\hline & & UKM & 2.065 & $<0.001$ \\
\hline & \multirow[t]{2}{*}{ UKM } & USM & -1.177 & $<0.001$ \\
\hline & & UM & -2.065 & $<0.001$ \\
\hline \multirow[t]{6}{*}{ Self-directed learning } & \multirow[t]{2}{*}{ USM } & UM & 0.097 & 1.000 \\
\hline & & UKM & 0.726 & 0.000 \\
\hline & \multirow[t]{2}{*}{ UM } & USM & -0.097 & 1.000 \\
\hline & & UKM & 0.629 & 0.002 \\
\hline & \multirow[t]{2}{*}{ UKM } & USM & -0.726 & $<0.001$ \\
\hline & & UM & -0.629 & 0.002 \\
\hline \multirow{6}{*}{$\begin{array}{l}\text { Career preference providing opportunity to serve the } \\
\text { community by joining general practice/community } \\
\text { medicine or family medicine. }\end{array}$} & \multirow[t]{2}{*}{ USM } & UM & 0.758 & 0.000 \\
\hline & & UKM & 0.710 & 0.001 \\
\hline & \multirow[t]{2}{*}{ UM } & USM & -0.758 & $<0.001$ \\
\hline & & UKM & -0.048 & 1.000 \\
\hline & \multirow[t]{2}{*}{ UKM } & USM & -0.710 & 0.001 \\
\hline & & UM & & \\
\hline
\end{tabular}

Table 2: Interns and their comparative level of community commitments and self-directed learning graded as below average (very poor to poor) average (fair) and above average (good to excellent)

\begin{tabular}{|c|c|c|c|c|c|}
\hline \multirow[t]{2}{*}{ Variable } & \multirow{2}{*}{$\begin{array}{l}\text { University of } \\
\text { supervisor's } \\
\text { graduation }\end{array}$} & \multirow{2}{*}{$\begin{array}{l}\text { University of } \\
\text { Intern's } \\
\text { graduation }\end{array}$} & \multicolumn{3}{|c|}{ Performance (frequency) } \\
\hline & & & Below average & Average & Above average \\
\hline \multirow{3}{*}{$\begin{array}{l}\text { 1. Contact with lost to follow up } \\
\text { patient }\end{array}$} & \multirow[t]{3}{*}{ UM } & USM & 1 & 3 & 20 \\
\hline & & UM & 6 & 8 & 10 \\
\hline & & UKM & 13 & 6 & 5 \\
\hline \multirow{3}{*}{$\begin{array}{l}\text { 2. Empathy with patient while in } \\
\text { clinical care }\end{array}$} & \multirow[t]{3}{*}{ UM } & USM & 1 & 5 & 18 \\
\hline & & UM & 10 & 6 & 8 \\
\hline & & UKM & 11 & 7 & 6 \\
\hline \multirow{3}{*}{$\begin{array}{l}\text { 3. Setting up family support for } \\
\text { patient }\end{array}$} & \multirow[t]{3}{*}{ UM } & USM & 1 & 6 & 17 \\
\hline & & UM & 10 & 6 & 8 \\
\hline & & UKM & 10 & 7 & 7 \\
\hline \multirow{3}{*}{$\begin{array}{l}\text { 4. Ensuring the sustainable } \\
\text { community support }\end{array}$} & \multirow[t]{3}{*}{ UM } & USM & 0 & 0 & 5 \\
\hline & & UM & 1 & 10 & 7 \\
\hline & & UKM & 4 & 6 & 7 \\
\hline \multirow{3}{*}{$\begin{array}{l}\text { 5. Ensuring drugs compliance when } \\
\text { important }\end{array}$} & \multirow[t]{3}{*}{ UM } & USM & 1 & 7 & 16 \\
\hline & & UM & 9 & 5 & 10 \\
\hline & & UKM & 11 & 6 & 7 \\
\hline \multirow{3}{*}{$\begin{array}{l}\text { 6. Counseling pts. to take doctor's } \\
\text { advise }\end{array}$} & \multirow[t]{3}{*}{ UM } & USM & 2 & 6 & 16 \\
\hline & & UM & 10 & 5 & 9 \\
\hline & & UKM & 14 & 6 & 4 \\
\hline \multirow{3}{*}{$\begin{array}{l}\text { 7. Paying home visits if pt. need } \\
\text { continuous care }\end{array}$} & \multirow[t]{3}{*}{ UM } & USM & 2 & 5 & 17 \\
\hline & & UM & 11 & 7 & 6 \\
\hline & & UKM & 11 & 9 & 4 \\
\hline \multirow{3}{*}{$\begin{array}{l}\text { 8. Participating in out-reach medical } \\
\text { camps }\end{array}$} & \multirow[t]{3}{*}{ UM } & USM & 1 & 5 & 18 \\
\hline & & UM & 9 & 6 & 9 \\
\hline & & UKM & 15 & 6 & 3 \\
\hline \multirow{3}{*}{$\begin{array}{l}\text { 9. Community visit to promote } \\
\text { health education. }\end{array}$} & \multirow[t]{3}{*}{ UM } & USM & 2 & 3 & 19 \\
\hline & & UM & 9 & 6 & 9 \\
\hline & & UKM & 17 & 6 & 1 \\
\hline
\end{tabular}




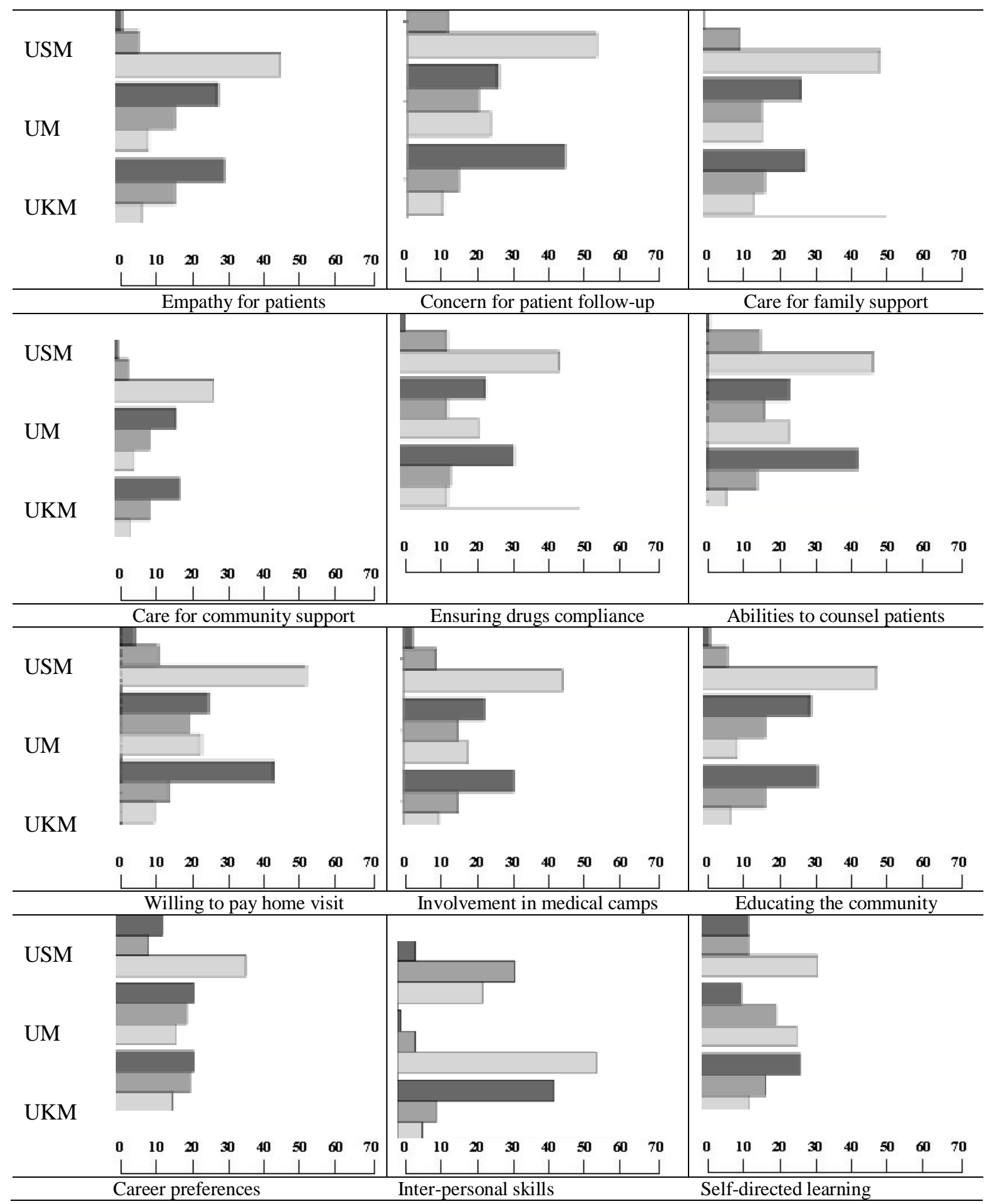

Figure 1: Supervisor's rating shown as below average (black), average (gray) and above average (light gray) of interns' attitude towards patient with respect to the 12 items.

\section{Discussion}

The main findings of the study indicate that USM graduates are more community oriented, conserved with a positive attitude and more inspired towards community health commitments. The USM graduates have a better mean score for all the variables related to community commitments and inspiration. This difference may be attributed to a comprehensive 
CBE program as CFCS taught throughout the five years of undergraduate curriculum. Most importantly, the interns as undergraduate medical students in USM have been working in the community under a duly organized CBE program, which starts with the student's survey on identification of health issues incorporating the community leaders. This helps to mobilize the community for the students' visit [12]. The survey includes the community felt health needs and a follow up that evaluates the student's work in the community. Evaluation of students by community members and peers are methods suggested by many authors [13].

Compared to this and very close to USM program UM has acquired COE program as CFCS in recent years. COE activity of UM also begins with students adopting the patients and following them up through the program. Their vision of community health needs is more focused to individual member (patient they adopt) rather than a jointly establish community health needs to be addressed as the impact of activities undertaken. Community health diagnosis is considered an important measure and impact that provides feedback to the community, which, helps to strengthen the partnership between the university and the community [14]. Students are expected to pay community visit twice a year, which is not sufficient for proper CBE program.

The UKM program on the other hand is an obvious COE program under which students association with the community is limited to a few visits (within 4 weeks) that precisely do not earmark on CBE philosophy, which virtually allows only one week learning in the community. The rest of the 3 weeks are consumed through lectures and community oriented activities away from the community. Supervisors pay visits and conduct lectures during this posting in which students have been putting up together in a rented hostel near village (community) visited.

The failure to involve community in students' lead activities and the lack of continuity and follow up in UKM and to some extend in UM program denies a collaborative partnership essential for an effective CBE curriculum. This makes the CBE program vulnerable to community exhaustion [15], which ultimately ends up in a one-way traffic that apparently favors student and institution interest but erodes the community's interest. The role of the community in health professions education has been well documented [16]. Community members should never be allowed to lose confidence in medical students as being novice and their work in community not seriously taken and completed on priority basis.

Practice to resolve community health issues once diagnosed in CBME program will strengthen and promote the student-community relationship, which can be utilized to seek community support for individual patients adopted by students. Response to variable 4 (sustainable community support) suggests that none of the 3 medical schools have scored adequately well, particularly USM (see table 3). This is an important finding and needs to be addressed in the curriculum. It is important for any CBE program to see the issues identified as community health diagnosis and if not addressed by one group of student's provision should be made for a succeeding student group to complete it [17].

Multiple comparisons by Bonferroni Post Hoc test in 3 variables suggest USM graduates more interested in community based practice compared to high-tech hospital based disciplines desired by the UM and UKM interns. However, the statement in questionnaire did not inquire directly about the specialization in other hightech hospital based disciplines. Self-directed learning also in favor of USM interns is considered an important component of CBME program. However, in inter-personal skills UM graduates predominantly performed better than others. Bias of supervisors being the graduate of the same institution for which they have to score over a global rating scale of excellent to very poor was also carefully analyzed. More than double the numbers of supervisors from UM (24=38.7\%) compared to USM (11=17.7\%.) have mostly assigned above average score to interns of USM (see table 1 and 3). 


\section{Conclusion}

The study provides sufficient evidence to favor CBME for Malaysian health care system when we analyze the community inspiratio and commitment of interns taught through a CBME curriculum (USM) verses a COE curriculum (UM) and (UKM). However, currently the medical school in UM is also practicing CBME as community and family case study (CFCS) whereas Medical faculty for undergraduate teaching in UKM continue to practice COE. Graduates from program of USM have shown positive attitude as public health professional who knows how to communicate and work with patients in community. Grading of most of the variables related to community commitment and inspiration gives a good understanding of the outcome objective of CBME program run by USM.

\section{Acknowledgement}

I would like to extend my gratitude and thanks to Gerard Majoor my supervisor in this project and A. Muijtjens, the statistician both from the department of Educational Development and Research, Maastricht Universiti. Also I would like to thank my wife Dr. Gauhar Taj Ansari and daughters Sabika, Rabika and Nabiha for their ever-ready support and help in compiling my thesis on this subject .

\section{Reference}

1. Lennox A. Development \& evaluation of community-based, multi-agency course for medical students: descriptive survey. British Medical Journal 1998:316:596- 599.

2. Seabrook MA, Lempp H, Woodfield SJ. Extending community involvement in medical curriculum: Lessons from a case study. Medical Education 1999; 33:838-845.

3. Dowell A, Crampton P, Parkin C. The first sunrise: An experience of cultural Immersion and community health needs assessment by undergraduate medical students in New Zealand. Medical Education 2001; 35:242-249.

4. Seifer SD, Hermanns K, Lewis J. Introduction. In: Seifer SD, Hermanns K, Lewis J, eds. Creating Community-
Responsive Physicians. Washington DC: American Association for higher Education 2000; 1-8.

5. Lasker RD \& the Committee on Medicine and Public Health Medicine and Public Health. The Power of Collaboration. New York: New York Academy of Medicine, 1997.

6. Bligh J. Tomorrow's Doctors: extending the role of public heath medicine in medical education. Medical Education 2002; 36:206207.

7. Schmidt H, Magzoub M, Felletti G, Nooman, Z, Vluggen P. Handbook of Community-Based Education (CBE): Theory and Practices. Maastricht: Network Publications, 2000.

8. PCDOMnet, 2001 http://www2.jaring.my/pcdom/7plan.htm. (Malaysian seventh national plan).

9. Harden RM. Sowden S. Dunn WR. Educational strategies in curriculum development, the SPICES model. Medical Education. 1984; 18(4): 284-97.

10. Rogayah J, Zulkifli A. Career preferences of medical students in a community oriented medical school Annals of Community Oriented Education,1993; 6: 301-310.

11. Ott L. Introduction to statistical methods and data analysis. 3rd ed. Boston PWS- KENT publishing company, 1988.

12. Omotara B, Yahya S, Amudu M, Bimba J. Awareness, attitude and practice of rural women regarding breast cancer in Northeat Nigeria. J Cmmunity Med Health Educ, 2012; 2: 148: doi: 10.4172/21610711.1000148

13. Magzoub ME, Schmidt HG, Abdel-Hammed AA, Dolmans D, Mustafa SE. Student assessment in community settings: A comprehensive approach. Medical Education, 1998; 32: 50-59.

14. Magzoub M, Schmidt H, Ilyas M, Lewis J. Impact of community - effects on the community. In H. Schmidt, M. (Eds), Handbook of Community-Based Education: Theory and Practices (pp. 11-26). Maastricht, Netherlands: Network Publications, 2000.

15. Joseph A, Abraham S. Making communitybased education programs sustainable? Education for Health, 2003; 16: 129-132.

16. Ezzat ES. Role of the community in contemporary health professions Education. Medical Education, 1995; 29(Suppl. 1): 4452. 
17. Williams RL, Reid, SJ, Myeni C, Pitt L, Solarsh G. Practical skills and valued community outcomes: the next step in community-based education. Medical Education, 1999; 33: 730-737.

Appendix 1: Questionnaire about community commitments, career preferences and self-directed learning of the graduates performing as interns.

\section{Variables (Items)}

1

The interns have good empathy with patients requiring psychological and emotional support

2 The interns have good follow up in contacting patients loosing contact with clinic when still needed.

3 The interns care for setting up the family support for patients

4 The interns ensure sustainable community support for the patients

5 The interns ensure good drugs compliance in case of chronic disorders requiring life long treatment

6 The interns are good at counseling and motivating patients to take doctors' advise

$\begin{array}{ll}7 & \text { The interns do not hesitate to pay home visit to }\end{array}$ patients requiring continue medical treatment

8 The interns participate regularly in out reach clinics organized by the department or NGOs

9 The interns pay community visits to promote health education

10 The interns career preference is more for G.P. or community medicine or family medicine

11 The interns have good inter-personal skills in getting on well with colleagues, patients and staff

12 The interns have good sense of self-directed learning continuing medical education

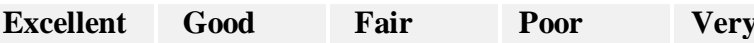

